\title{
Queer Resistances in the Adult Animated Sitcom
}

\author{
Stewie Griffin: “And then I think to myself: My God, wouldn't it be marvelous if I turned out to be a \\ homosexual? (Family Guy, Season 2, Episode 19, 18 July 2000)"
}

In spring 2009, a new episode of Family Guy entitled 'Family Gay' (Season 7, Episode 8, 8 March 2009) stirred up discussion on AfterElton ${ }^{1}$, an LGBT community driven website which comments on popular culture and its queer representations within popular culture. In the contested episode, the main character Peter Griffin is injected with the 'gay gene' and transforms into a flamboyant queer. Some online comments featured viewers taking offense at the series' reiteration of stereotypes and lack of positive messages, while others defended the series, applauding its conscious refusal of political correctness, pointing to the fact that the show similarly portrayed non-queer characters in a stereotypical manner. This discussion fits within the larger debate on the role of queer ${ }^{2}$ representations in contemporary Western culture. Several scholars (e.g., Avila-Saavedra 2009; Becker 2006; Davis \& Needham 2009; Hart 2000) have argued that despite the significant increase of queer characters and themes in television fiction, popular television series still reiterate dominant ideologies that reinforce heteronormativity and oppress queerness. Their argument draws on a queer theoretical perspective, which proposes that our Western contemporary society grants discursive power to the heterosexual matrix (see Butler 1999; Halberstam 2005; Sedgwick 1985; Warner 1999). The matrix relies upon fixed notions of gender, sexuality, and identity, and veils its constructedness and anomalies by feigning universality and rendering the heteronormative discourse hegemonic. In this way, it succeeds in excluding those who do not comply or conform. Since hegemonic discourses are materialized through and within different 
societal institutions, including the media industries, popular culture also perpetuates heteronormative ideals.

Recently, animated sitcoms have begun to incorporate queer characters and queer themes. For instance, The Simpsons legalizes gay marriage in 'There's Something About Marrying' (Season 16, Episode 10, 20 February 2005), American Dad discusses same-sex adoption in 'Surro-Gate' (Season 3, Episode 7, 2 December 2007), and King of The Hill brings the coming-out story of a character's father in 'My Own Private Rodeo' (Season 6, Episode 18, 28 April 2002). In accordance with queer media theory's critique of popular culture's reiterations of heteronormativity, the representation of queer themes or characters does not per se defy the heterosexual norm. Jeffery P. Dennis $(2003,137)$ stresses that contemporary animated series only portray tolerance towards a queer identity while the context often remains that of hegemonic heterosexual desire. Yet Stuart Hall $(2005,71)$ argues that popular culture cannot be regarded as only reiterating hegemonic discourses. Because of its ability to function as a site where production, text, and reception interact, and meaning is constantly renegotiated, popular culture - particularly television —is part of both a struggle for and against hegemonic discourses. Hall thus implies that popular culture can embed articulations of resistance, or, because of the potential polysemy of texts, can be read against the grain. Both strategies allow using the popular as a means to expose the mechanisms and inconsistencies of discourses on the one hand and to offer viable alternatives to the heteronormal on the other.

With this article, we want to point out how the adult animated sitcom articulates instances of queer resistance. The genre is characterized by its mixture of animation and traditional sitcom conventions. It draws on the established genre conventions, but uses postmodern textual strategies to transcend genre boundaries, criticize and/or mock 
contemporary popular culture, and target both young and adult audiences. In this regard, Simone Knox $(2006,73)$ argues that adult animated series like Family Guy are marked with a certain "double-codedness", since they are commercially viable and hugely popular ${ }^{3}$ while being critically praised for their often blatant satire or subversiveness. She draws on Linda Hutcheon (2002, 11), who looks upon postmodern culture as articulating complicity and critique, thus inscribing and subverting dominant conventions and ideologies at once. With regard to this duplicity, Hutcheon (2002, 23, 178-79) and Max H. Kirsch (2000, 28-31) underscore the similarities in objectives and strategies of queer and postmodern practices. They argue that even though both practices refrain from offering a straightforward theory of agency, they nonetheless unsettle, expose, and subvert normative discursive practices by relying on irony and parody. Hence, these practices are predominantly occupied with deconstructing hegemonic discourses. We thus argue that a study on the adult animated sitcom's articulations of queer resistance needs to be discussed from a perspective that incorporates the genre's postmodern textual strategies. To this end, we conducted a textual thematic analysis of five episodes of Family Guy that feature queer characters and/or themes. This case study functions as both an illustration and exploration of the potentialities and limits of queer resistance within this postmodern genre.

\section{Pastiche, Parody and the Adult Animated Sitcom}

Ever since The Simpsons (1989-) went on the air, the adult animated sitcom genre has gained international success with popular series such as King Of The Hill (1997- ), South Park (1997-), Daria (1997-2002), Family Guy (1999- ), and American Dad (2005- ). Clearly, the genre has achieved a prominent spot in contemporary Western popular culture. The Simpsons has succeeded in re-establishing animation as a prime-time genre, since the early 1960s boom 
in prime-time animation headed by The Flintstones (1959-1966) and other series by HannaBarbera Productions failed to maintain drawing major audiences (Booker 2006, ix-xii; HiltonMorrow \& McMahan 2003, 77-78). The Simpsons set the tone for knock-offs to come by creating a postmodern genre that satirizes suburban life and presents itself as a parody of American popular culture, and in particular of the archetypical family sitcom (Booker 2006, 48). On the surface, these animated sitcoms remain true to the generally appraised image of the American neurotic middle-class family. But at the same time, the concept of family is used to subvert many (hetero-)normative values. The genre joins in a range of comedic television series (e.g., Married With Children (1987-1997), Modern Family (2009-)) that share the urge to 'laugh' at the impossibility of traditional images that were being portrayed in archetypical family sitcoms. However, the genre's subversive take on the family differs from the enacted comedic series' approach, since the latter is predominantly shaped by codes of realism and naturalism. The adult animated sitcom relies on animation, which makes it possible to push the boundaries further when it comes to portraying subversive views (Tueth 2003, 139-41). According to Jonathan Gray (2006), animation has the advantage of creating a distance between audiences and the text that "softens the blows on the viewer's moral sense, highlighting that 'it's only a cartoon"' (p. 67). Yet he considers that animation gives parody more options to formulate critique because the potential of exaggeration and literalization increases and the social and cultural verisimilitude can easily be transgressed. Further, taking into account that the genre frequently employs intertextuality as a representational strategy, animation enables infinite intertextual representations. Since intertextuality provokes the textual dominance of hegemonic discursive meanings and defies the exclusion of resistant or oppositional meanings, it ensures the genre's potential to question the discursive power of hegemonic discourses (Gray 2006, 39-40, 66). 
The interplay of postmodern strategies and the animated aesthetic can result in parodies resistant to dominant institutions, practices, norms and values. Hence, we cannot agree with Fredric Jameson's (2006) critical statement that parody has been replaced by pastiche in a postmodern era. He postulates that postmodern culture is, most of all, a culture of pastiche, characterized by a refusal or neglect to diverge from or oppose norms and conventions. He considers it to be 'blank parody' because it mimics and imitates the past but “without any of parody's ulterior motives, amputated of the satiric impulse, devoid of laughter and of any conviction that alongside the abnormal tongue you have momentarily borrowed, some healthy linguistic normality still exists" (p. 493). Since Gray (2006, 5-109) argues that The Simpsons incorporates both moments of pastiche and significant parody, and acknowledges the series' critical potential, we are inclined to follow Hutcheon (2002) who considers parody to be central to postmodernism. In contrast to Jameson, she argues that parody is a reprise of the past articulated through a critique. She stresses that parody is about showing how current representations derive from past ones, and articulating its complicity to the past by continuing representational conventions, and its critique to the past by subverting these conventions (Hutcheon 2002, 89).

The adult animated sitcom applies both techniques of parody and pastiche centrally, since this genre not only engages in parody but also uses pastiche to affect audiences, whether by evoking reflection or laughter. Particularly adult animated series use the postmodern as a means for comedy (Steeves 2005). Even though comedy has the potency to offer a critique of normality through exposing invisible aspects of everyday life and turn them into visible irrationalities (Gray 2006, 106-07), pleasure can also come from recognizing the original that has been faithfully mimicked. We therefore agree with Dyer (2007) that pastiche is an affective articulation which "allows us to feel our connection to the affective frameworks, the 
structures of feeling, past and present, that we inherit and pass on" (p. 180). Pastiche, like parody, thus sets up a relation to the past and makes explicit how feelings and thoughts are always dependent upon the frameworks available in a certain time and place. Parody and pastiche thus both aid in creating a site for deconstructing discourses through reinstating and subverting them, rather than actively and blatantly articulating political strategies of agency or formulating straightforward counter-discourses.

\section{Looking for Queer Deconstructions}

Since the adult animated sitcom is situated at the crossroads between complicity, questioning, and critique, the genre does not offer concrete political stances or transgressive counter-discourses. However, as argued before, its critical value resides in the intertextual provocations and subversions that deconstruct universalized notions of hegemonic discourses. In this article, deconstruction will be discussed as a form of queer resistance. Because queer theory is largely indebted to post-structuralism, deconstruction is at the core of queer theoretical enterprises (Seidman 1995, 125-31). Deconstructive analysis can resist discourses of heteronormativity and homosexuality, by exposing how they construct fixed and oppositional gender and sexual identities, and consolidate heteronormative hierarchies. In particular queer deconstructions look at contradictions and frictions in identity articulations, and focus on the margins to critically assess the heteronormative centre. On the other hand scholars who employ queer deconstructive analysis recognize that a text is polysemic and thus opens up different reading positions. According to Alexander Doty (2000, 1-3), popular culture products incorporate as much queerness as they incorporate straightness. The only difference between both is that the queer reading is not the preferred reading. Doty stresses the importance of sharing these alternative readings to broaden our shared knowledge of 
interpretations of the same text. However, aside from lending its strategies to queer reading practices, deconstruction can also function as a strategy of representation. Queer resistance is then articulated in queer themes and/or characters and exposes or disrupts normative patterns and notions from within. Particularly, in the adult animated sitcom, the contradictions and frictions concerning gender and sexuality are explicated by the genre's postmodern textual strategies, such as exaggeration, literalization, or intertextuality, whether or not intended as pastiche or parody. In addition the genre benefits from the unique ability of animation, as Sean Griffin (2004, 106-08) rightly points out, to easily unsettle gender and sexual categories by its frequent use of metamorphosis or parodic redeployment. These deconstructions then function as textual disruptions, exposing heteronormativity rather than offering a queer political agenda.

Even though many of the contemporary animated sitcoms are suitable for a thorough inquiry of deconstructionist instances of queer resistance ${ }^{4}$, we chose to solely look into Family Guy. The series, created by Seth McFarlane, has become a competitor to the yellow empire of The Simpsons. Like The Simpsons, it features an all-American suburban middle class family, the Griffin family, which includes a working father (Peter Griffin), a stay-athome mother (Lois Griffin), three children (Meg, Chris, and Stewie Griffin) and a family pet (Brian). However, Family Guy places less emphasis on narrative storylines than The Simpsons, adds surreal identity traits to some of its characters, while at the same time embedding them into a contemporary reality. Furthermore, its display of sexual tainted humor, political incorrectness, and bigotry has led the series into a realm of controversy and debate that has fast surpassed any surrounding The Simpsons (Needham 2009, 147; Booker 2006, 81). The controversy is often linked to the series' predominant subtext of queer sexuality, which makes Family Guy a crucial case study for queer resistance. The series' 
references to queerness abound, ranging from quick allusions to episodes fully dedicated to queer-related themes. This article relies on an in-depth thematic textual analysis of five episodes of Family Guy that feature queerness as a main theme (e.g., debating same-sex marriage, gender confusion, establishing a sexual identity). In particular, we examine how the series applies postmodern strategies to create queer resistance through instances of parody and pastiche. To this end, we first scrutinize Family Guy's strategies of intertextuality. Subsequently, we focus on the series' use of exaggeration, literalization, and hyperstereotyping.

\section{Intertextuality}

Full of references to past and contemporary popular culture, Family Guy clearly relies on intertextuality to depict queer characters and themes. Particularly, through instances of intertextual pastiche and parody, the series unsettles heteronormative values and norms that are part of the picture-perfect representation of the nuclear family. For instance, in the series' opening credits, a pastiche is created of former traditional family sitcoms. It begins with Lois playing the piano and singing: "It seems today that all you see is violence in movies and sex on TV." Peter then jumps in and continues the song: "But where are those good old-fashioned values on which we used to rely?" Up to this point, the credits can be interpreted as a tribute to the opening credits of the 1970s satirical sitcom All in the Family (1968-1979). Both theme songs similarly value the days of yore and deplore the changing mores and times. From the moment the other Griffin members join in and start chanting that "Luckily there is a family guy," the opening credits take a different spin. The credit sequence transforms the home environment into a show hall where, to the sound of a cheerful brass band and a background choir, the Griffins star in a variety show. They are all dressed in matching yellow costumes, 
yet gendered to the degree that the female characters are wearing stockings. Seen from one perspective, the series' opening credits work as a consolidation of traditional family values and clear gender divisions. Yet these credits derive their parodic power through their juxtaposition with the content of each episode in which precisely those 'family values', referenced nostalgically, become ridiculed and revealed as unsustainable. From a queer perspective, it thus exposes the discourse of heteronormativity as a discourse that in the course of each episode will be mocked, uncovered, or defied, without abolishing it or replacing it with viable counter-discourses.

Thus, even though the opening credits do not feature explicit queer themes, they subversively and strategically reflect on heteronormativity from within a conventional paradigm. The series explicitly reiterates and challenges contemporary discourses on queer sexuality through such intertextual references. In the episode 'Brian Sings and Swings' (Season 4, Episode 19, 8 January 2006) Meg is mistakenly read as a lesbian. In contrast to traditional sitcoms or soaps, Meg does not mind being considered a lesbian. It grants her a welcome party by the Gay and Lesbian Alliance Club, a girlfriend and a social life. She starts embodying iconic lesbian identity traits (a ripped orange flannel shirt, spiky hair, and a butch attitude) and comes out to her family. She announces, in close-up, to her parents that she has to tell them something: "Mom, dad, I am a lesbian." While Peter considers that "awesome", Lois is more skeptical. She does not believe her daughter is a lesbian, even though she stresses that she would accept her if she was indeed gay. Meg tackles Lois's 'disbelief' retorting that what matters to her is that her lesbian friends have accepted her, adding that she hates her mother because she does not seem to care for her struggle. Meg thus falls back on an essentialist identity discourse. She claims a fixed lesbian identity, and stresses that she has to come to terms with 'being' a lesbian by going through an identity struggle. Such discursive 
identity positions and practices in itself do not question the way heteronormativity governs identities. Nor does it challenge the power granted to straight-identifying persons to decide whether or not to accept the queer. Lois's speech, in which she says she would accept her daughter if she was "gay, blind, or retarded" strengthens such heteronormative supremacy. Nonetheless, parody is already present in the textual exaggeration of the outdated yet still uttered assumption of looking upon homosexuality as a physical disability by putting it on a par with blindness or mental retardation. Furthermore, Meg's lesbian identity performance parodies the assumption that identity articulations are merely utterances of a fixed sexual identity. The second coming-out scene at the end of the episode continues to parody the process of coming out. In this scene, Meg uses the same language she initially employed to come out as straight to her girlfriend Sarah: "For the first time in my life, I felt like I belonged. And so I pretended to be something I'm not." Here, the series transgresses its former 'copy' of the coming-out scene and reverses the procedure by the end of the episode. A straight girl comes out to a queer girl, subverting the omnipresent story of a queer coming out to a heteronormative majority. Furthermore, by bringing a 'fake' and then a reversed coming-out scene, the series exposes the coming-out narrative as a popular intertextual narrative ready for comical and/or critical appropriation. However, by letting Meg assume her former straight identity, an essentialist perspective on identity is re-established. Yet, the restoration of this essentialist identity discourse does not imply that it cannot be re-defied. In particular, as Sarah utters her disappointment in Meg by reproaching her for 'choosing' to be a heterosexual, the series teases out the social constructionist and queer theoretical perspective on identity.

The series also applies intertextual strategies to mock the articulations and reiterations of a heteronormative perspective on gender and sexuality in popular culture. In particular, it 
tackles the role genre conventions of popular culture products assume in foregrounding hegemonic discourses and precluding others. For instance, in the beginning of 'I Am Peter, Hear Me Roar' (Season 2, Episode 8, 28 March 2000), when Peter offends a female coworker and is therefore sent to a women's retreat to get in touch with his feminine side, Peter's boss tries to ensure that his company promotes gender equality. To this end, the company coerces its workers to view a mandatory video that shows how men should behave around female colleagues. In a cutaway scene, the video appears as a black-and-white 1950s documentary. A costumed host informs men about women and demonstrating how one should address them. The documentary taps into the conventions of a nature documentary, describing and depicting women as curious animals: "Irrational and fragile by nature, female co-workers are a peculiar animal." By using the format of documentary, the series exposes how a 'neutral' voice may easily be infused with a heteronormative or sexist agenda, and how narrative and cinematographic codes intervene in the process of distributing and creating 'realist' queer representations or 'objective' knowledge on issues of gender and sexuality. A similar rendering and implicit critique of such codes occurs in the episode 'You May Now... Uh... Kiss the Guy Who Receives' (Season 4, Episode 25, 30 April 2006). In this episode Lois is having doubts about whether or not to support gay marriage. When she consults her priest for his opinion, he shows her a celluloid film made by God himself. It begins as a 1950s film supposedly produced by the notorious religious right spokesperson Pat Robertson, entitled 'The Homosexual and You'. The show ridicules this religious right product, while exposing the heteronormative assumption that there is a difference between normal people, who are directly addressed, and deviant others. The video turns out to be a contemporary product with a male host in an office, which reads as a parody of the television infomercial where an office signifies the presenter as an authority. The host promises the audience a few tips on how to know whether "you" are dealing with a gay. Only two tips are shown, each illustrated with a 
re-enacted scene. In the first scene, two men are sitting on a couch. According to the host, asking the other man for his favorite Madonna album may reveal whether or not he is dealing with a gay. Since the other man answers that he likes her early work, he is marked by a postproduced red stamp that reads 'gay'. Since Madonna is considered a gay icon, the series mocks the common stereotype that one's popular cultural preferences may come from or correspond to one's sexual orientation. Besides, it underscores how mainstream society tries to maintain a rigid binary divide between heterosexuality and homosexuality, to the extent of making it abnormal for heterosexual men to enjoy Madonna. The second scene examines this further. It shows a man being examined by a doctor. The voice-over informs us that "if instead of human blood, you find a deadly, corrosive acid, you've got a gay." The documentary then changes into a horror picture as a giant monster comes out of the chest of the man who is just diagnosed as 'gay'. The monster gets shot to death by the doctor, while the voice-over comments: "Not this time, Nancy boy." Where the former scene mocks the linear relation between one's music taste and one's sexuality, the latter renders the very quest into and exposure of one's sexuality ridiculous. Furthermore, the transformation of the gay character into a grotesque and horrific monster reads as a satire of homosexual panic. In general, Family Guy invests in the interplay between animation and intertextuality to exaggerate and deconstruct the ubiquitous practice of exploiting genre conventions to the benefit of hegemonic discourses.

Finally, popular culture icons, symbols, or events are sometimes re-imagined as queer as a strategy to think beyond the heteronormative set of signs that denote gender or sexuality. Especially in the multiple cutaway scenes, where the characters' fantasies and memories are visualized. For instance, in the episode 'Family Gay', Peter namedrops a few celebrities who were married while being, in fact, widely known as gay, such as Rock Hudson. However, he 
concludes his list with Ronald Reagan. This leads to a cutaway scene of a press conference where Ronald Reagan and Mikhail Gorbachev are commenting on the missile pact. Reagan answers the questions by alluding three times to the anal sex they supposedly had the other night. One of the journalists sees through the "butt-fucking puns" and asks them politely to refrain from further witticism. What this scene does is, on the one hand, imagine queerness in characters who would not otherwise be considered queer, while at the same time, through the neutral reaction of the journalist, make such 'impossible' queerness feasible. On the one hand, the series thus employs intertextuality to mock popular icons by queering them. However, the intertextual strategy also invites audiences to critically reconsider how their perspective may be constructed by discursive strategies precluding oppositional or resistant discourses. ${ }^{5}$ This is also illustrated in the episode 'Brian Sings and Swings', in which Brian tells us about that time Peter swam with the bulls. The show then visualizes an elegant water ballet recital to the gentle score of Tchaikovsky's Waltz of the Flowers, performed by beefy built bulls and Peter. Since the performance receives high scores from the jury, the scene aims for laughs through its concurrence of physical masculinity and perfectly executed 'feminine' performance. Nonetheless, it represents successful non-normative masculine behavior, and engages once more in re-imagining the traditional masculinity of Peter (cf. supra). Moreover, this scene also illustrates how the series challenges and re-imagines its own characters' heteronormative behavior. In a similar move, the series repeatedly subverts the explicit heteronormative and homophobic speech of Stewie by representing his fantasies as infused with queerness (e.g., cross dressing or homo-erotic desires). Consequently, the discourse of heteronormativity is never safeguarded in the series, rather is always on the verge of being dismantled.

\section{Exaggeration, Literalization, and Hyper-Stereotyping}


Apart from intertextuality, Family Guy relies on strategies of exaggeration, literalization, and hyper-stereotyping. These strategies are chiefly characterized by their dependence on animation techniques. Since the animated aesthetic grants the genre more freedom in representation, articulations of queer resistance need to be evaluated within that context. First, using exaggeration, the series succeeds in transgressing those boundaries that most enacted television shows pursue in order to uphold a level of credibility and reality. The logics of time and place are most often neglected, and limits of body and materiality are bent to fit the logics of fiction rather than of reality. As such, Stewie can easily look like a baby, talk like an adult and always be one year old. However, exaggeration does not only imply the creation of surreal reality and corporeality. In particular, in relation to queer identities and desires, the series uses exaggeration to make fun of queerness on the one hand, and on the other, celebrate it by representing it as desirable and preferable. For instance, in the episode 'Family Gay', Peter decides to move in with his boyfriend Scott. They inhabit an apartment in West Quahog, the gay district. Their queer domesticity is represented in a scene showing their first evening together. The lovebirds are enjoying a glass of red wine in their fancily decorated apartment. They are dressed classy, yet wearing outfits that are coded as 'gay', and articulate their love for one another by saying "I am so gay for you." On the one hand, this scene works as a reiteration of stereotypes and induces heteronormativity through upholding the binary divide between queer and straight sexuality, and stressing the differences through the 'gay' setting, 'gay' clothing, and 'gay' way of expressing love. On the other hand, the perfected setting, the subtle use of purple color schemes, the sugary candle light dinner, and the domestic happiness all evoke a queer domesticity that is both stylish and desirable. The scene reveals an idealized domesticity that is not 'straight' and that subverts the pictureperfectness of a heteronormative idealized domesticity. 
With the strategy of literalization, the series uses animation to render the figurative literal. Potential queer resistance then comes using the animated images to expose the heteronormative gaze of audiences and characters. In the episode 'To Love and Die in Dixie' (Season 3, Episode 12, 15 November 2001), the family has to enroll in a witness protection program in the south of the United States. Chris befriends a local boy named Sam with whom he pokes dead people and wanders around town. Sam seems very fond of Chris and in one scene he kisses Chris passionately. Chris is shocked, but most of all confused. He acknowledges that the kiss felt right but he does not seem keen on a romantic relationship. At this point, the series did not include or exclude the possibility that Chris might be reconsidering his sexuality. The plot thickens when Sam turns out to be a girl. Even though the episode had constructed Sam as masculine, it never established biological gender. Because of a few animated iconic elements such as a lower voice, boyish dungarees, and a cape, Sam was represented as a boy, whereas the exposure of long blonde hair and breasts renegotiated Sam's gender into female. Interestingly, Chris freaks out because he often experiences unease whenever he is around girls, even though he has been portrayed as desiring girls. The ambivalence is prolonged to the point where Chris admits that he cannot talk to girls but only to boys, upon which Sam suggests that Chris should think of Sam as a boy. Chris agrees on the idea by joyfully saying: "Yes, sir!" This episode starts with literalizing the common assumption that biological sex equates gender by articulating Sam as male through an exclusive use of iconic traits of masculinity. Thus, instead of articulating gender traits as figurative aspects that connote specific social, cultural or emotional behavior, gender traits are only represented as literal markers of a biological sex. However, this applied literalization is used to 'trick' the audiences and Chris into thinking of Sam as a boy. It also makes the exposure of Sam as a girl more radical, which fortifies the dismantling of the essentialist assumption of fixed, binary and causal relationships between biological sex and gender. Most 
interestingly, the ambiguous response of Chris to Sam also teases out articulations of resistance. The confused Chris is only able to be intimate with a female if he imagines her as a male, yet, without feeling desire for a male body. The episode may end with a heterosexual romance, but the queered gender relationship between Chris and Sam allows us to look upon the young lovers as positioned outside of the realm of heteronormativity.

Finally, most of the heated debate on Family Guy, and adult animation in general, concerns the series' frequent stereotyping. However, with regard to the adult animation sitcom, we agree with Gray $(2006,64)$ who considers this rather a practice of hyperstereotyping. Its intention is not to mock the social minorities, but rather the process of stereotyping. With regard to queer characters, Family Guy offers a wide range of stereotypes. Two of the studied episodes in particular revel in clichés. In 'You May Now... Uh... Kiss the Guy Who Receives', Brian's gay cousin, Jasper, comes over to Quahog to visit the family and marry his boyfriend Ricardo. Since Jasper is a talking dog and Ricardo a mute Filipino, identity traits of being different are linked to a queer identity. Furthermore, Jasper's effeminate speech, witty humor, swishy gestures, and a limp wrist represent Jasper as a 'flaming scene queen'. The range of iconic stereotypes becomes emphasized in the scene where Jasper takes the family to a Greek restaurant. At dinner, he complements Lois's earrings: "Lois, darling, those earrings are delicious. Total kitsch like an Andy Warhol wet dream. I'm opening a museum and putting you in it, they're that fabulous." The witty articulation, the reference to queer icon Andy Warhol and the sexual innuendo can all be considered queer clichés. It is Stewie who exposes the reiteration of queer articulations, when he says:

\footnotetext{
You think it's clever talking like that? You think it's funny talking about earrings, and using words like 'fabulous', and 'delicious' and 'wet'? What's next? A workout followed by a romp around a crowded room, while the music goes 'thump', 'thump' 'thump'? (Season 4, Episode 25, 30 April 2006)
} 
Ironically, Jasper and Ricardo do not seem to mind Stewie's mocking remarks, as they start dancing to his imitated beat. Further, since Stewie can equally be considered queer, the joke is rather on Stewie. Even more, the exaggeration of the queer stereotypes rather reveals how easily queers are considered 'other' due to the hegemony of heteronormativity.

The 'Family Gay' episode stresses this even more by transforming both Peter's traditional masculinity and heterosexuality. His reversal to queerness is articulated through a significant amount of different queer-coded outfits (leather and flashy pants, colorful tight shirts, a red tank top, a pink scarf), different haircuts, and an earring. Furthermore, he articulates and accentuates his queerness by thriving on effeminate speech and behavior, a sudden interest in cooking and decorating, witty and sexual remarks, and a queer-coded lifestyle (cocktails, queer literature, watching Lifetime television, an apartment in the gay neighborhood). However, it is not only Peter who performs the stereotypical queer. In the last scene, where Peter's final fantasy of having an eleven-way comes true, nine semi-naked men walk out of the bedroom. Even though ethnically diverse, they all move exactly the same way as if they were a pastiche of one another. Reproaching such a scene as only a reiteration of stereotypes would be ignoring that, through repetition and exaggeration, the series once again parodies the essentialist perspective that considers a queer identity as universal, up to a shared interest in popular culture trivia.

\section{Reiteration, Reversal and Restoration}

The previous illustrations have shown how postmodern strategies create a text that allows it to be read as being able to both reiterate and reverse hegemonic discourses. Because of this duplicity, the series refrains from taking up political positions but nonetheless creates 
content that can be interpreted as resistant. For instance, in the episodes 'I Am Peter, Hear Me Roar' and 'Family Gay', Peter diverges from his traditionalist masculinity. In the first episode, he gets in touch with his feminine side, while in the latter episode he becomes an effeminate gay man. Both episodes thus transform Peter into a queer character, exaggerating his femininity and queerness in a similar way his traditional masculinity is often being enlarged. In letting Peter embody different masculinities, the series succeeds in offering temporal reversals of the hegemonic heteronormative masculine identity. It even teases the traditional Peter by making queer Peter more attentive to the needs of his family and friends. Yet it reiterates binary and traditional assumptions on gender and sexuality. Notwithstanding Peter's self-comfort with his femininity and queerness, his friends and family are having trouble with the new Peter. They express their longing for the old family guy, and respond mostly awkward to the queered version of Peter. For instance, Lois prefers Peter in conventional gender and marital roles, just like his friends prefer Peter with a traditional beer rather than an exotic cocktail. Also, Peter's new gender and sexual identities are represented as positioned into a binary and oppositional relation to heterosexual masculinity. Nonetheless the series continually steers between reiteration and reversal, for instance by letting queer Peter seduce the ladies-man Quagmire, who eventually agrees on 'doing it', as long as they do it his way.

The deconstructive instances that temporally exposed and disrupted the discourse of heteronormativity do not, however, prevent each episode from reinstalling the nuclear family in its original form. This leads Needham $(2009,108)$ to conclude that the series never succeeds in challenging the normative institution of family, since the ongoing subversion is aborted at the end of each episode, leaving the heteronormative family in hegemonic pole position. We agree with Needham that often at the end of the queer-themed episode 
heteronormativity is restored. Peter regains his masculinity in 'I Am Peter, Hear Me Roar', Meg resigns from claiming a lesbian identity in 'Brian Sings and Swings', and Peter's homosexuality wears out in 'Family Gay'. Even more, at the end of the latter episode Peter states: “Thank God everything's back to normal!” However, right after Peter says thanks for a return to normalcy, a dead horse is thrown violently through the window ${ }^{6}$. Family Guy may thus seem to restore the happy heteronormative beginning of each episode, but the dead horse makes explicit the absurdity and impossibility in such a happy ending. Foremost, the restoration should be seen as an inherent genre convention. At the core of a sitcom lies the element of a situation that needs to be resolved (Kutulas 2005, 69). As Gray (2006, 51) argues, the twenty-two minute time limit, intrinsic to the sitcom genre, forces these series to create a happy ending in the last minute. Family Guy thus reinstates the 'heteronormal', since it depends upon this condition of 'normalcy' to challenge it in the next episode - whereas, if there is nothing 'normal' to challenge, the series would lose its appeal in parodying the normative.

Queer resistances in the adult animation sitcom thus most likely reside in between the articulations of complicity and critique, sometimes masked as pastiches putting outdated stereotypes of queerness to the fore, and sometimes as parodies holding normative and repressive practices up to mockery. 


\section{Notes}

${ }^{1}$ The discussion can be followed at http://www.afterelton.com/blog/lylemasaki/imho-family-guy-family-gay.

${ }^{2}$ Queer is here considered as referring to those who do not consider their sexual identity and/or desires as strictly heterosexual, and/or articulate sexual and gender identity positions that are considered as diverging from the heteronormal.

${ }^{3}$ In 2006 for instance, Knox $(2006,73)$ reports The Simpsons being broadcast in more than seventy countries reaching more than sixty million viewers.

${ }^{4}$ South Park, for instance, often engages in representing provocative storylines that dissect through parody the different ways Western society deals with queerness. We refer to Ted Gournelos (2009) and Jasbir Puar (2007) who both made meticulous analyses of the series' queer politics by focusing on the ambivalent and transgressive character Mr./Ms. Garrison.

${ }^{5}$ Yet, we stress that not all audiences will engage with the intertextuality of the text, nor pick up on the resistant meanings embedded in the text. To this end, we agree with Hollis Griffin (2008) who points out that series employing a parodic mode of address create ambivalent texts which may be interpreted differently, depending on the viewer. With regard to parodic representations of queerness, and in particular in the program Reno 911 ! (2003-2009), Griffin concludes that some viewers may laugh at queer representations and the queerness that is being mocked, while other viewers may laugh at the queer characters.

${ }^{6}$ In the beginning of the episode, Peter had to get rid of the body of a dead horse. His solution was to place the horse on the hood of his car, to drive up to a window of the pharmacy and finally hit the brakes in front of the window, which made the horse crash into the window. The pharmacist takes revenge in the final scene of the episode and crashes the horse into the window of the Griffins. 


\section{References}

Avila-Saavedra, Guillermo. 2009. Nothing Queer About Queer Television: Televized Construction of Gay Masculinities. Media, Culture \& Society 31 (1): 5-21.

Becker, Ron. 2006. Gay TV and Straight America. New Brunswick, NJ: Rutgers University Press.

Booker, M. Keith. 2006. Drawn to Television: Prime-Time Animation from the Flintstones to Family Guy. Westport, CT: Praeger Publishers.

Butler, Judith. 1999. Gender Trouble: Feminism and the Subversion of Identity. 2nd ed. London and New York: Routledge.

Crawford, Alison. 2009. “Oh Yeah!”: Family Guy as Magical Realism? Journal of Film and Video 61 (2): 52-69.

Davis, Glyn, and Gary Needham, eds. 2009. Queer TV: Theories, Histories, Politics. London and New York: Routledge.

Dennis, Jeffery P. 2003. “The Same Thing We Do Every Night”: Signifying Same-Sex Desire in Television Cartoons. Journal of Popular Film \& Television 31 (3): 132-40.

Doty, Alexander. 2000. Flaming Classics. New York: Routledge. 
Dyer, Richard. 2007. Pastiche. Oxon and New York: Routledge.

Gournelos, Ted. 2009. Popular Culture and the Future of Politics: Cultural Studies and the Tao of South Park. Lanham, MD: Lexington Books.

Gray, Jonathan. 2006. Watching with the Simpsons: Television, Parody, and Intertextuality. New York: Routledge.

Griffin, Hollis. 2008. Queerness, the Quality Audience, and Comedy Central's Reno 911! Television \& New Media 9 (5): 355-70.

Griffin, Sean. 2004. Pronoun Trouble: The Queerness of Animation. In Queer Cinema: the Film Reader, edited by Harry Benshoff and Sean Griffin, 105-18. New York: Routledge.

Halberstam, Judith. 2005. In a Queer Time and Place: Transgender Bodies, Subcultural Lives. New York and London: New York University Press.

Hall, Stuart. 2005. Notes on Deconstructing 'the Popular'. In Popular Culture: A Reader, edited by Raiford Guins and Omayra Zaragoza Cruz, 64-71. London: Sage.

Hart, Kylo-Patrick R. 2000. Representing Gay Men on American Television. Journal of Men's Studies 9 (1): 59-79. 
Hilton-Morrow, Wendy and McMahan, David T. 2003. The Flintstones to Futurama:

Networks and Prime Time Animation. In Prime Time Animation, edited by Carol A. Stabile and Mark Harrison, 74-88. London: Routledge.

Hutcheon, Linda. 2002. The Politics of Postmodernism. 2nd ed. London and New York: Routledge.

Jameson, Fredric. 2006. Postmodernism, or the Cultural Logic of Late Capitalism. In Media and Cultural Studies: Keyworks, edited by Meenakshi Gigi Durham and Douglas M. Kellner, 482-519. Malden: Blackwell. Originally published in New Left Review 146 (July-Aug. 1984): 53-92.

Kirsch, Max H. 2000. Queer Theory and Social Change. London and New York: Routledge.

Knox, Simone. 2006. Reading the Ungraspable Double-Codedness of the Simpsons. Journal of Popular Film \& Television 34 (2): 72-81.

Kutulas, Judy. 2005. Who Rules the Roost? Sitcom Family Dynamics from the Cleavers to the Osbournes. In The Sitcom Reader. America Viewed and Skewed, edited by Mary M. Dalton and Laura R. Linder, 49-59. Albany, NY: State University of New York Press.

Needham, Gary. 2009. Scheduling Normativity: Television, the Family, and Queer Temporality. In Queer TV: Theories, Histories, Politics, edited by Glyn Davis and Gary Needham, 143-58. London and New York: Routledge. 
Puar, Jasbir. K. 2007. Terrorist Assemblages: Homonationalism in Queer Times. Durham, NC: Duke University Press.

Sedgwick, Eve Kosofsky. 1985. Between Men. New York: Columbia University Press.

Seidman, Steven. 1995. Deconstructing Queer Theory or the under-Theorization of the Social and the Ethical. In Social Postmodernism: Beyond Identity Politics, edited by Linda J. Nicholson and Steven Seidman, 116-41. Cambridge, UK: Cambridge University Press.

Steeves, H. Peter. 2005. "It's Just a Bunch of Stuff That Happened": The Simpsons and the Possibility of Postmodern Comedy. In The Sitcom Reader: America Viewed and Skewed, edited by Mary M. Dalton and Laura R. Linder, 261-71. Albany, NY: State University of New York Press, 2005.

Tueth, Michael V. 2003. Back to the Drawing Board: The Family in Animated Television Comedy. In Prime Time Animation, edited by Carol A. Stabile and Mark Harrison, 133-46. London: Routledge.

Warner, Michael. 1999. The Trouble with Normal. Cambridge, MA: Harvard University Press. 